\title{
Experimenting the Effectiveness of Traditional vs Modern Learning of Web Technologies among Computer Professional Students
}

\author{
N. R. Ananthanarayanan, $\mathrm{PhD}$ \\ Associate Professor \\ Dept of CSA \\ SCSVMV University \\ Kanchipuram,India
}

\author{
M. Kannan, PhD \\ Assistant Professor \\ Dept of CSA \\ SCSVMV University \\ Kanchipuram,India
}

\begin{abstract}
The objective of the study is to analyze the opinion about traditional and online learning methods with respect to course, content, teacher and reachability. Keeping this in view, a software study was conducted and which was aimed to develop the learning tool which is known as "Knowledge Connection" for Sank-Hara Computer Centre for Education and Learning. It is an intranet/internet based learning tool based on blended learning methodology. Pre Hypertext Processor, Apache Web Server and Mysql as the back end and other tools such as Dream weaver were used to create a learning model and SPSS 20 were used to interpret the results. Sample of 100 respondents were taken for the study based on simple random sampling method. The findings reveal that the students are much more interested towards online environment based on their mean value. This study is unique in the sense that new user friendly learning tool have been deployed to test the results. The results will be helpful to introduce more number of online courses which can be incorporated in the syllabus to enrich more knowledge towards knowledge society.
\end{abstract}

\section{Keywords}

Traditional, Online learning, Knowledge-Connection, Blended learning, Knowledge society

\section{INTRODUCTION}

This project analyzes the effectiveness and viability of traditional v/s modern learning of web technology course among computer programming students. Sank-Hara Computer Centre for Education follows the concept of traditional talk and chalk methodology, where faculty delivers the programming techniques by giving examples and illustrations which are expressed by the way of talk and chalk methods. The drawback in traditional method of teaching and learning works well only for students with the homogenous group. Keeping this in mind the learning tool was developed known as "Knowledge Connection". Administrator can install Knowledge Connection by using EASYPHP. Educators can create online materials using PowerPoint, Interactive Flash Content, and redistribute intranet-based course content to easily retrieve the content, and conduct their courses online It helps to keep track of learner's progress in the course by online discussions with the mentor on a particular topic or lesson. This learning tool keeps track of assigning and displaying grades and assessing student's performance and also tracks learning path details of the student. It initiates a student's collaborative environment between the faculty and the student. The online learning content can be generated by the faculty, in-house, so that the students can study the programming material, required number of times to gain more knowledge. Students were given a user-id and password to login to the learning tool and browse the programming materials which are designed by the faculty.

\section{LITERATURE REVIEW}

Aisha A.Othman, Crinela Pislaru and Ahmed M.Impes[1] analyzed issues on the design, development and implementation of blended learning strategy at faculty of science,omer-al-mukthar university, Libya. A. Seda Yucel [2] has stated that Internet has been widely spread and used for not less than ten years; however, it has changed the contents of many concepts in our day to day lives as a modern communication tool.

Ru-Chu Shih[3] studied on the globalization and the advent of Information and Communication Technology. This study aimed to establish a bridge between blended teaching and learning model combining online and face to face instructional blogging for an English course. To foster this, a Blended-Learning course following the Inverted Classroom model as part of the faculty development curriculum has been developed for a blended learning scenario for English course.

Ghanshyam and Inder Singh Thakur[5] analyzed that IT is penetrating into school education. Lots of companies are coming up with digital material for school students. Many are making specialized hardware to meet the requirements of elementary education system.. In past few years due to decrease in the price of computer hardware and other electronic gadgets, many educational institutes are opting for digital study material for their students.Jonathan [6] examined the role and effectiveness of hybrid course offerings within the higher education context. Muzafer Saracevic, Esad Međedović, Sead Mašović, Faruk Selimović, Hamza Kamberović [7] gave an idea on the extensive literature and its characteristics of successful online teaching and the introduction of good pedagogy in online learning environment, there are still only very few studies on the consequences of online learning on students and teachers, and even less about the ways in which online learning can be shaped in the traditional classroom teaching

Research findings of Sharon Yam and Peter Rossini[8] shows that the traditional face-to-face discussion in the workshop was an effective form of informal formative assessment where students found it useful for their summative weekly test, and the class attendance was significantly related to student performance.

Chandra Reka Ramachandiran and Nazean Jomhari,[9] Examined the e-Learners perception on pedagogical virtual agents and their Kansei experiences with the sample of 105 undergraduate students. 


\section{STATEMENT OF THE STUDY PROBLEM}

Traditional method of teaching and learning takes place wherein teachers take the role of felicitation and students are the recipient of information of knowledge. It encourages oneway communication; therefore, the teacher must make a conscious effort to become aware of student problems and student understanding of content without verbal feedback. It requires a considerable amount of unguided student time outside of the classroom to enable understanding and longterm retention of content. In contrast, interactive methods (discussion, problem-solving sessions) allow the teacher to influence students when they are actively working with the material. It requires the instructor to have or to learn effective writing and speaking skills. Keeping in mind the above mentioned aspects into consideration, the feasibility analysis was conducted and the learning tool KnowledgeConnection was developed to supplement the need of the students

\section{OBJECTIVES OF THE STUDY}

1. To study the methodology of teaching and learning at Sank-Hara Education and Learning.

2. To improve and enhance the learning content online rather than traditional content.

3. To improve and measure the teacher performance in terms of traditional learning and online learning.

4. To view the factors influencing the satisfaction and dissatisfaction relevance towards learning tool

5. To evaluate and measure the student learning performance with regards towards online and also using traditional learning methods

\section{SCOPE OF THE STUDY}

The study titled "Experimenting The Effectiveness of Traditional Vs Modern Learning of Web Technologies Among Computer Professional Students" covers the aspects of teachers and students who are using the learning tool "Knowledge Connector" with regards to course related factors, learning content, and also the teacher knowledge towards teaching and learning traditionally and also the online reachability with regards to students learning methods towards online learning

\section{MATERIALS AND METHODS \\ 6.1 Information and Communication Technology Integration at Sank-Hara Computer Centre for Education and Learning}

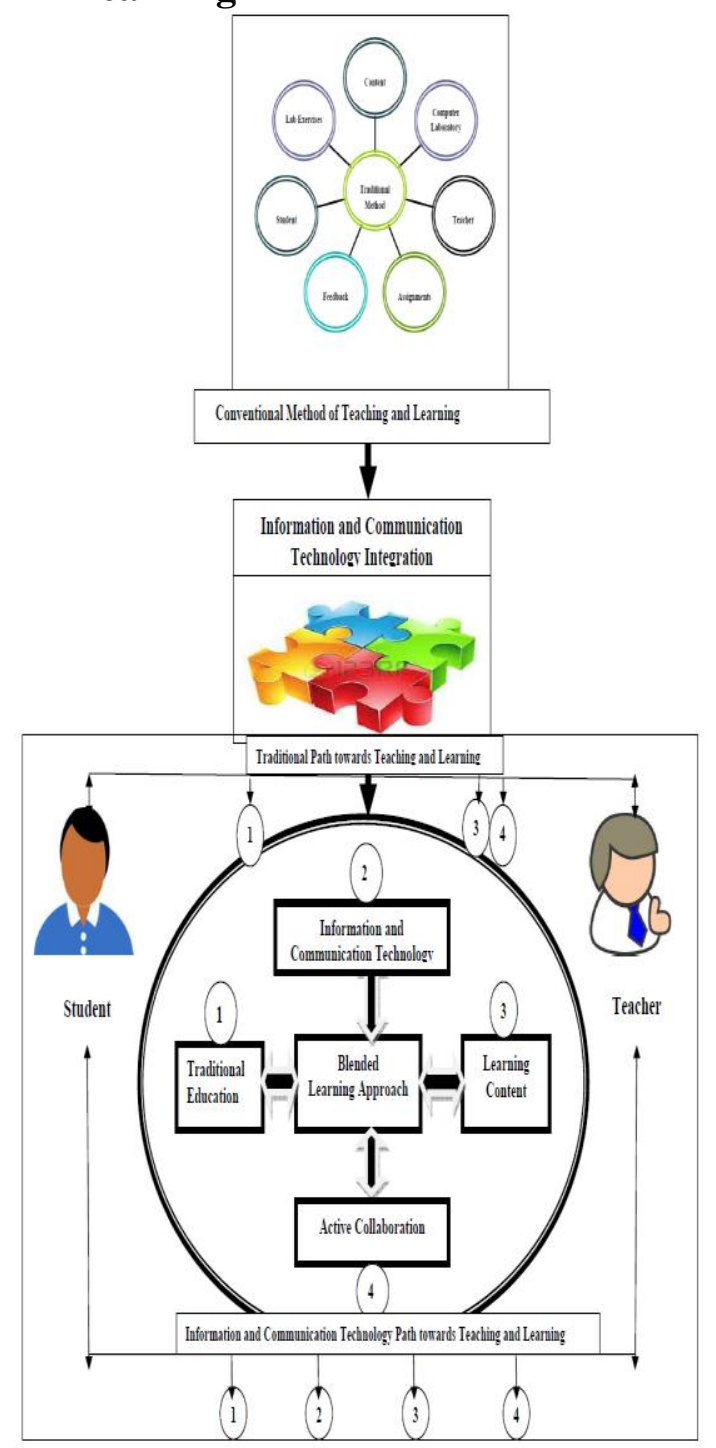

Figure-1: Integration of ICT into Teaching and Learning Process at Sank-Hara Computer Center for Education and Learning

Traditional teaching is concerned with the faculty being the controller of the learning environment. Student's control, power and responsibility are held by the faculty and they play the role of instructor (in the form of lectures) and decision maker (in regards to curriculum content and specific outcomes). They regard students as having 'knowledge holes' that need to be filled with information and knowledge. In short, the traditional faculty views that it is the faculty that causes learning to occur. Learning is chiefly associated within the classroom and is often competitive in nature as shown in Figure-1.

Due to advances in Information and Communication Technology which changed the scenario of education in particular in pedagogy and instructional process of teaching and learning is more lucrative and productive in creating 
collaboration, learner centered and interactive environments. Therefore information dissemination through Information and Communication Technology plays a constructive role in education to make the teaching and learning process more effective through active collaboration in an information rich society. Learning content can be digitized, stored, zipped and can be sent through the variety of wide range of components such as communication devices as well as the various services and applications associated with ICT such as videoconferencing and distance learning as shown in Figure1 .

The students can be given Learning content in the form of ebook, animations and interactive web based learning materials as a learning material. The same is developed for the students which must be meaningful in the active analysis, synthesis and evaluation of information. It is a challenging task to segregate Learning content into Unit / Lesson/ Topic/Chapters. In our study JavaScript, HTML subjects are taken under consideration as Unit/ Lesson/Topic/Chapters. Lesson plan is made for JavaScript and HTML subjects. The aim of the lesson plan is to make it objective based which has to be written clearly and it is being split into knowledge, skill and appreciation lessons. Each lesson is divided into suitable units so that the students can understand it gradually. Illustrations and examples are applied in JavaScript and HTML subjects. The online materials which are uploaded in the intranet site are to be regularly updated. Learning materials are very user friendly to the students and also helps in achieving the learning objective individualized and student centered. They can actively collaborate with the fellow students about the lessons in which they have learned to enrich their knowledge. Lessons are prepared in such a way that students can cover the entire syllabus without wide range of difficulty wherein students can enter and exit from the learning content at any point of time. Students can repeat the lesson as many times as a skill building exercise. It is more grounded with pedagogical values emphasizing on inquiry based, active or problem based learning as shown in Figure-1.

\subsection{Software Modules in Knowledge Connection}

\section{Student Interface}

Professor
Interface
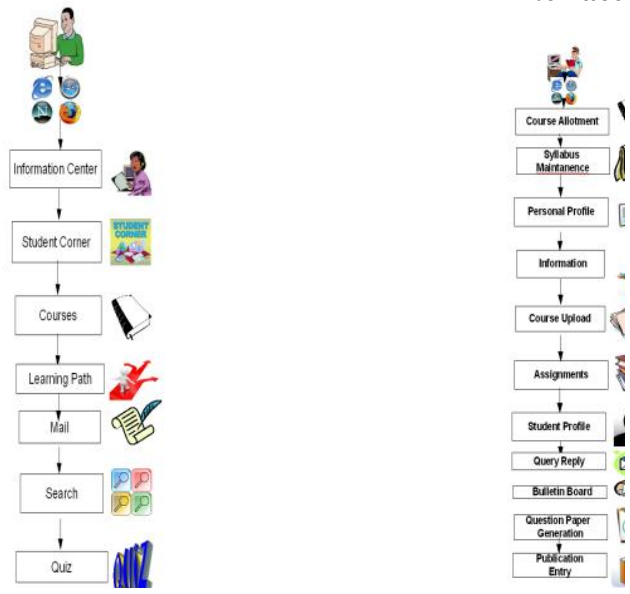

Figure-2: Software Modules in Knowledge Connection

Knowledge Connection tool comprises of Student and Teacher interface as software components as shown in Figure-2.

\section{Student Interface}

- Information Center: This software component displays information about Assignments Deadline given by the faculty and also Weekly Examinations and other related details.

- Student Corner: This guides the student on exam tips, health tips, and positive thinking attitudes towards xamination

- Courses: This component diplays various numbers of topic/lessons for a particular course.

- Learning path: The route, taken by a learner through a range of (commonly) e-learning activities in a sequential manner, which allows them to build knowledge progressively.

- Mail: This is an intranet mail where student can send the mail to the professor on a particular subject to the faculty.

- Search: Search facility is used for searching materials for a particular topic/lesson/course.

- Online Quiz: After completion of the course every student has to undergo an online quiz and he/she can guide themselves where they stand.

Teacher Interface

- Course Allotment: This module will allocate subject allotment such as course code, name of the course, duration, internal test etc.,

- Syllabus Maintenance: Syllabus for B.C.A., B.Sc(CS), MCA(Regular) ,MCA(Lateral Entry) and M.Phil(CS) is stored in the database.

- Faculty Information: Faculty profile can be updated frequently on national conference, seminars, workshop etc..

- Course Upload: Professor will upload as a Topic/Lesson/Unit to the students. Where in the student has to download the content.

- Assignments: Every professor uploads assignments to the students where it takes care of Assignment-ID, Title, Assignment Deadline date etc.

- Student Profile: Maintains student assessments such as I and II internal test marks, lab marks etc.,

- Query Reply: This is used for answering the queries that are initiated by the students.

- Bulletin Board: A system that enables users to send or read electronic messages and other data that are of general interest and addressed to no particular person.

- Question Paper: This module performs tasks related to paper setting like part-a 2 marks and part-b 12 marks 2 questions from each unit.

- Publication Entry: Professor who has published papers in international journals, national journals, conferences etc are stored in the database. 
- Student Database: Professor maintains database profile of all the students such as assignment marks, internal marks etc.,

- Authoring Tool: An authoring tool is a program that has pre-programmed elements for the development of interactive multimedia software titles. Authoring systems can be defined as software that allows its user to create multimedia applications for manipulating multimedia objects.

\section{DATA ANALYSIS AND INTERPRETATION}

\subsection{Demographic Profile}

Among 100 respondents $64 \%$ of the respondents belong to engineering category and $36 \%$ of the respondents belong to master of computer applications category. $60 \%$ of the respondents belongs to male category, $40 \%$ of the respondents belongs to female category. $64 \%$ of the respondents belong to BE (CSE) category, $26 \%$ of the respondents belong to MCA category and $10 \%$ belongs to MCA (Integrated) category. $44 \%$ of the respondents belong to urban category, $28 \%$ belongs to rural category and $28 \%$ belongs to semi urban category.

\subsection{Opinion about Traditional Learning- Course}

Table-1 and Figure- 3 shows the factors which influence the traditional learning using talk and chalk methodology.

Table1: Opinion about Traditional Learning Course

\begin{tabular}{|l|c|}
\hline \multicolumn{1}{|c|}{ Factors } & Mean \\
\hline Objectives & 2.48 \\
\hline Expectation & 2.46 \\
\hline Unit Arrangement & 2.48 \\
\hline Viability & 2.32 \\
\hline Duration & 2.40 \\
& \\
\hline
\end{tabular}

Source: Primary data

Table- 1 and Figure- 3 shows in traditional learning method the respondents were asked to rate on Objectives, Expectation, Unit Arrangement, Viability and Duration. It was found that the means of Objectives (Mean=2.48) and Unit Arrangement (Mean 2.48) were found be the same, it is concluded that the Unit arrangement and Objectives were strongly related to each other. It was also found that the Expectation (Mean 2.46) is closely related to Objectives and Unit Arrangement.

\section{Learning Course}

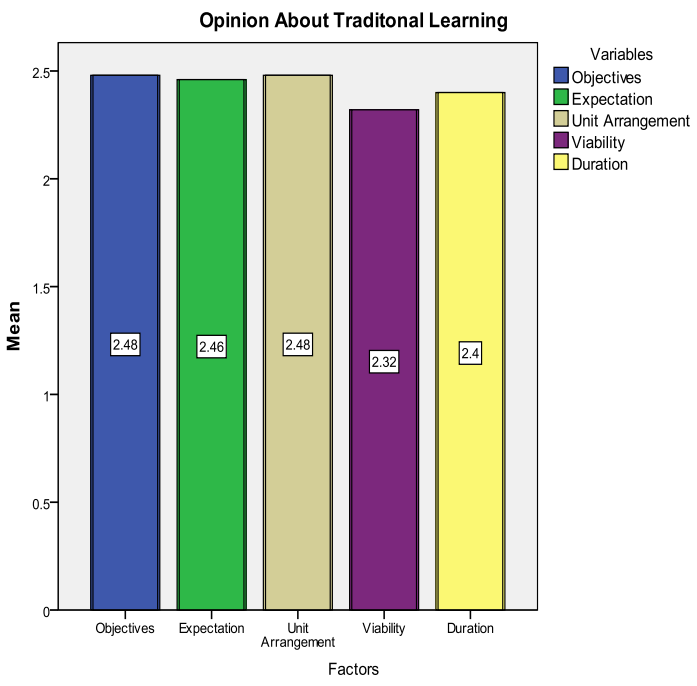

Figure-3:Factors which influence Traditional Learning Course

\subsection{Traditional Learning Content}

Table- 2 and Figure- 4 shows the factors which influence the learning content in terms of coverage, depth, sequence and presentation, explanation, illustration, language, application, user interface and test questions.

Table2: Opinion about Traditional Learning Content

\begin{tabular}{|l|c|}
\hline Factors & Mean \\
\hline Coverage & 2.56 \\
\hline Depth & 2.12 \\
\hline $\begin{array}{l}\text { Sequence \& } \\
\text { Presentation }\end{array}$ & 2.26 \\
\hline Explanation & 2.46 \\
\hline Illustration & 2.26 \\
\hline Language & 2.46 \\
\hline Application & 2.32 \\
\hline User Interface & 2.46 \\
\hline Test Questions & 2.42 \\
\hline
\end{tabular}

Source: Primary data

From the table- 2 and figure- 4 it is observed that coverage $($ Mean $=2.56)$ plays a vital role in traditional learning content. 


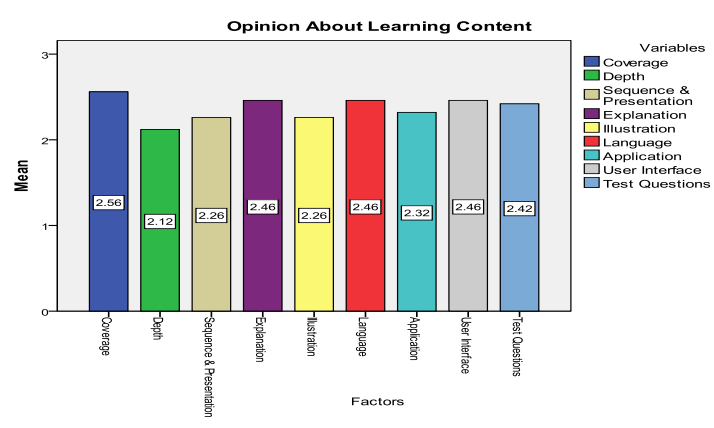

Figure-4: Factors which influence Traditional Learning Content

\subsection{Teacher influence in Traditional Teaching and Learning Methods}

Table-3 and Figure-5 shows the factors which influence the teacher coverage using traditional learning methodology on subject knowledge, delivery, interaction, communication, enthusiasm, subject clarity, subject delivery, experience in the subject, subject coverage, presentation and lab exercises related to the subject were discussed and analyzed.

Table-3: Opinion about Traditional Teaching and Learning Methods

\begin{tabular}{|c|c|}
\hline Factors & Mean \\
\hline Subject Knowledge & 2.46 \\
\hline Delivery & 2.44 \\
\hline Interaction & 2.48 \\
\hline Communication & 2.42 \\
\hline $\begin{array}{c}\text { Usage of Visual and } \\
\text { Audio Aids }\end{array}$ & 2.22 \\
\hline $\begin{array}{c}\text { Enthusiasm } \\
\text { Sustained Interest }\end{array}$ & 2.18 \\
\hline Clarity & 2.34 \\
\hline $\begin{array}{c}\text { Empathy in Delivery } \\
\text { Experience in the Subject }\end{array}$ & 2.38 \\
\hline $\begin{array}{c}\text { Duration to cover the } \\
\text { subject }\end{array}$ & 2.56 \\
\hline Presentation & 2.48 \\
\hline Lab Exercises & 2.36 \\
\hline
\end{tabular}

Source: Primary data

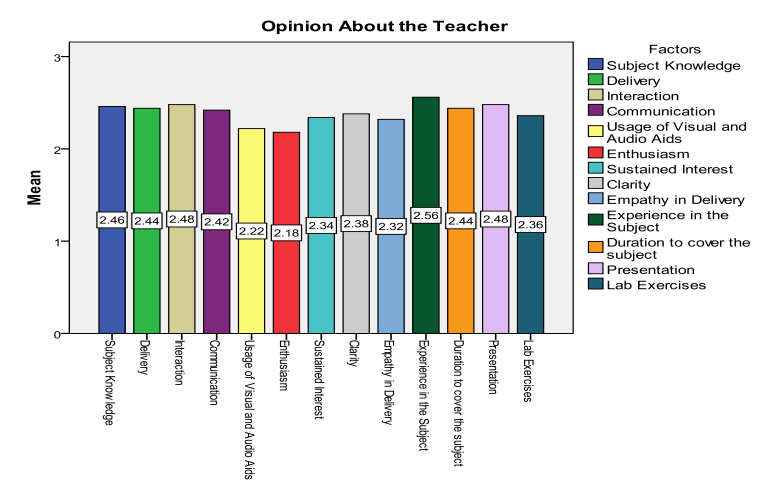

Figure-5: Factors which influence about the opinion on the teacher

It is observed from Table-3 and Figure-5 shows that Experience in the Subject (Mean: 2.56) which influences that the teachers are more experienced in teaching the subject to the students. It is from the analysis that the Subject Knowledge (Mean: 2.46) influences, that the teacher are very good in imparting the subject knowledge to the students. It has also been observed that the Delivery (Mean: 2.44), and Interaction (Mean: 2.48) has a relation with the subject knowledge of the teacher. It is very well understood that the Communication (Mean: 2.42) between teachers and students is well established knowledge connection in the subject expectation, unit arrangement, viability and duration

\subsection{Opinion about Online Learning Course}

Table-4 and Figure- 6 shows the factors relating to online learning which consisting of objectives, expectation, unit arrangement, viability and duration.

Table 4 : Online Learning

\begin{tabular}{|l|c|}
\hline \multicolumn{1}{|c|}{ Factors } & Mean \\
\hline Objectives & 2.52 \\
\hline Expectation & 2.56 \\
\hline Unit Arrangement & 2.56 \\
\hline Viability & 2.32 \\
\hline Duration & 2.62 \\
\hline
\end{tabular}

Source: Primary data

It is observed from Table- 4 and Figure- 6 shows that the online learning Duration (Mean: 2.62) which states that the students enjoy online learning. Objectives (Mean: 2.52), Expectation (Mean: 2.56), Unit Arrangement (Mean: 2.56) suggests that Expectation, Unit Arrangement matches with the online learning objectives. 


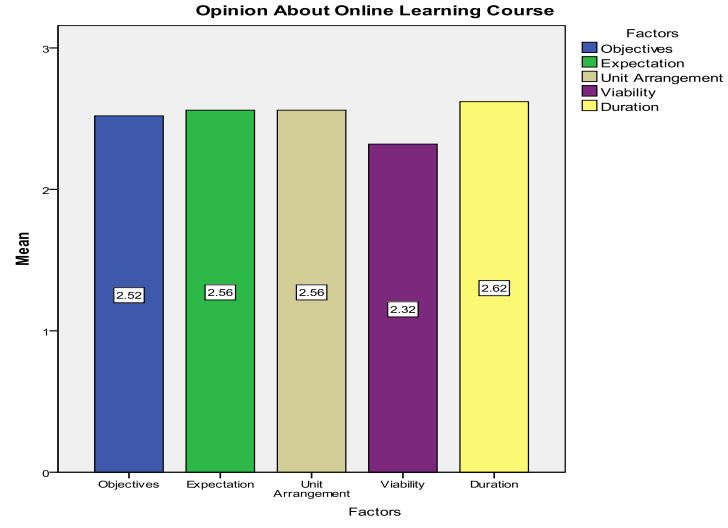

Figure-6: Factors which influence about Online Learning Course

\subsection{Opinion about Learning Content in Online Learning}

Table-5 and Figure-7 shows the factors which influence the online learning content which is a combination of text, image, audio, video, hyperlinks known as learning objects (Learning Content). It has been observed that in Table-5 and Figure-7 shows the learning content coverage which has the (Mean: 3.06) describes that the online learning content meets the expectations of the students and also the objectives which is define already in the learning content. Sequence and Presentation which has the (Mean: 2.64) value suggest that the learning content sequence and presentation has an remarking effect in the minds of the students. In case of learning content Depth (Mean: 2.44), the learning content which meets the standards of the learning objects. The software is multilingual language supported, students can choose the language he is going to learn the learning content. Language (Mean: 2.74). The User Interface (Mean: 2.62) is user-friendly to the students, The Test Questions (Mean: 2.64) is sequential/ random in order so that the students will not able to see the other questions directly.

Table 5: Factors which influence Online Learning Content

\begin{tabular}{|l|c|}
\hline Factors & Mean \\
\hline Coverage & 3.06 \\
\hline Depth & 2.44 \\
\hline Sequence \& Presentation & 2.64 \\
\hline Explanation & 2.48 \\
\hline Illustration & 2.38 \\
\hline Language & 2.74 \\
\hline Application & 2.58 \\
\hline User Interface & 2.62 \\
\hline Test Questions & 2.64 \\
\hline
\end{tabular}

Source: Primary data

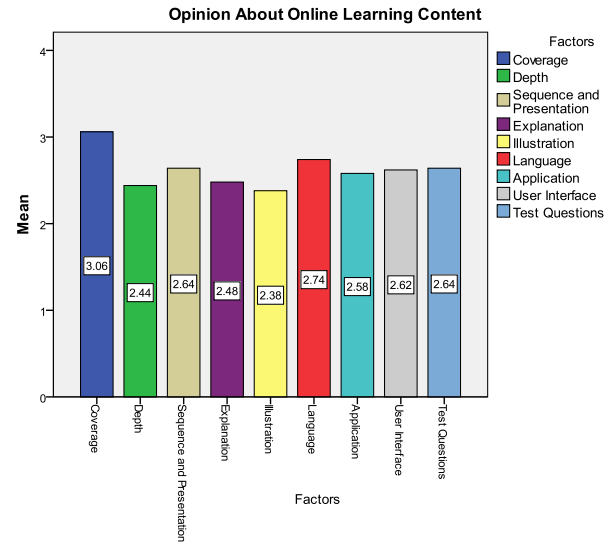

Figure-7: Factors which influence Online Learning Content

\subsection{Opinion about Reachability towards Online Learning}

Table-6 and Figure- 8 shows the reachability matrix components which cover the factors such as subject knowledge, delivery, interaction, communication, usage of visual and audio aids, enthusiasm, sustained interest, clarity, empathy in delivery, experience in the subject, duration to cover the subject, presentation and lab exercises.

Table-6: Factors which influence Reachability Components toward Online Learning

\begin{tabular}{|c|c|}
\hline Factors & Mean \\
\hline Subject Knowledge & 2.68 \\
\hline Delivery & 2.52 \\
\hline Interaction & 2.34 \\
\hline Communication & 2.50 \\
\hline Usage of Visual and Audio & 2.22 \\
\hline Aids & 2.44 \\
\hline Enthusiasm & 2.42 \\
\hline Sustained Interest & 2.58 \\
\hline Clarity & 2.30 \\
\hline Empathy in Delivery & 2.58 \\
\hline Experience in Subject & 2.64 \\
\hline Duration to cover the subject & 2.62 \\
\hline Presentation & 2.56 \\
\hline Lab Exercises & \\
\hline
\end{tabular}

Source: Primary data

It has been observed from table- 6 and figure- 8 shows that the subject knowledge (Mean: 2.68) has increased the students knowledge towards online learning. The Communication (Mean: 2.50) regards to the video and voice communication of the teacher to the students in online learning has changed the students mind to concentrate more on online learning. The other factors such as Enthusiasm(Mean: 2.44), Sustained Interest(Mean: 2.42), Clarity(Mean: 2.58), Duration to cover the subject (Mean: 2.64), Presentation (Mean:2.62), Lab 
Exercises(Mean: 2.56) has increased considerably in online learning.

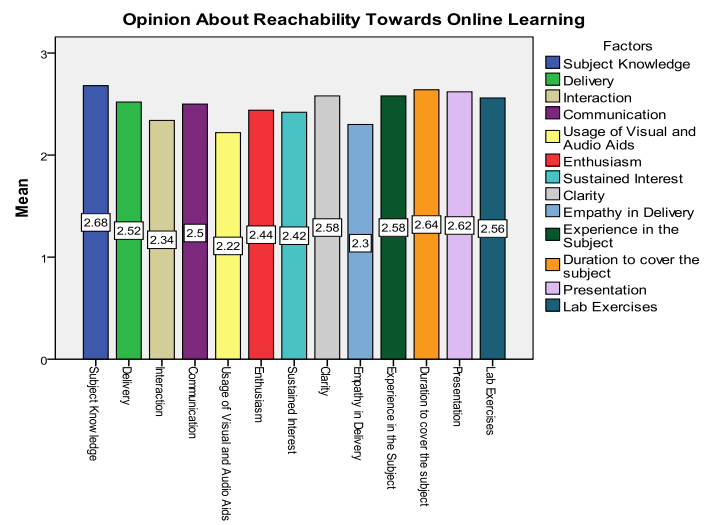

Figure-8: Factors which influence reach ability towards Online

\subsection{COMPARISON BETWEEN}

TRADITIONAL AND ONLINE

LEARNING TOWARDS COURSE

Table-7 and Figure-9 describes the comparative analysis of traditional and online learning towards course.

Table7: Course Comparison between Traditional and Online Learning

\begin{tabular}{|c|c|}
\hline COURSE & MEAN \\
\hline Traditional & 2.42 \\
\hline Online & 2.51 \\
\hline
\end{tabular}

Source: Primary data

From Table-7 and Figure-9 shows a comparative analysis was made between traditional and online learning about the course. The Mean Value of Traditional Learning Course is 2.42 and that of Online learning Course is 2.51. It is evident that the online learning is more effective than traditional learning. It is evident from the fact that in Traditional Learning Course the mean values of Objectives(Mean:2,48), Expectation(Mean:2.46), Unit Arrangement(Mean:2.48) and duration(Mean:2.40) is comparatively less than the mean values of Online learning Objectives (Mean:2.52), Expectation(Mean:2.56), Unit Arrangement (Mean:2.56) and Duration(Mean:2.62).

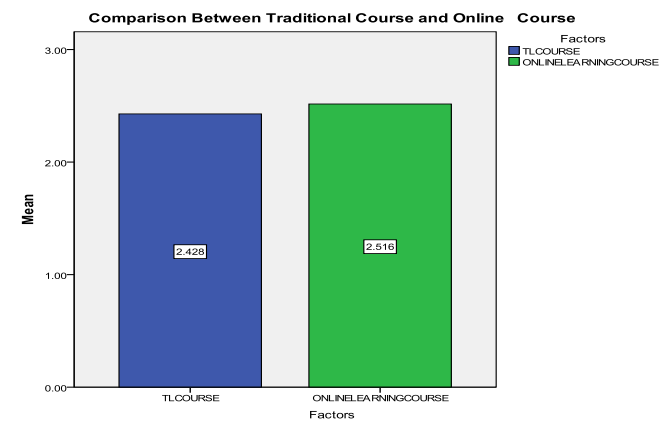

Figure-9: Comparison between Traditional and Online Learning Course

\subsection{COMPARISION BETWEEN TRADITIONAL AND ONLINE LEARNING TOWARDS LEARNING CONTENT}

Table- 8 and Figure-10 describes the comparative analysis of traditional and online learning towards course.

Table 8: Learning Content Comparison between Traditional and Online Learning

\begin{tabular}{|c|c|}
\hline LEARNING CONTENT & MEAN \\
\hline Traditional & 2.36 \\
\hline Online & 2.62 \\
\hline
\end{tabular}

Source: Primary data

From Table- 8 and Figure-10 shows a comparative analysis was made between traditional and online learning about the learning content. The Mean Value of Traditional Learning Content is 2.36 and that of Online learning Course is 2.62. It is evident that the online learning content is more effective than traditional learning content. The Mean Values of Traditional Learning Content was observed Coverage (Mean: 2.56), Explanation (Mean: 2.46), User Interface (Mean: 2.46) is less than the online learning content mean values. Coverage (Mean: 3.06), Explanation (Mean: 2.48) and User Interface (Mean: 2.62).

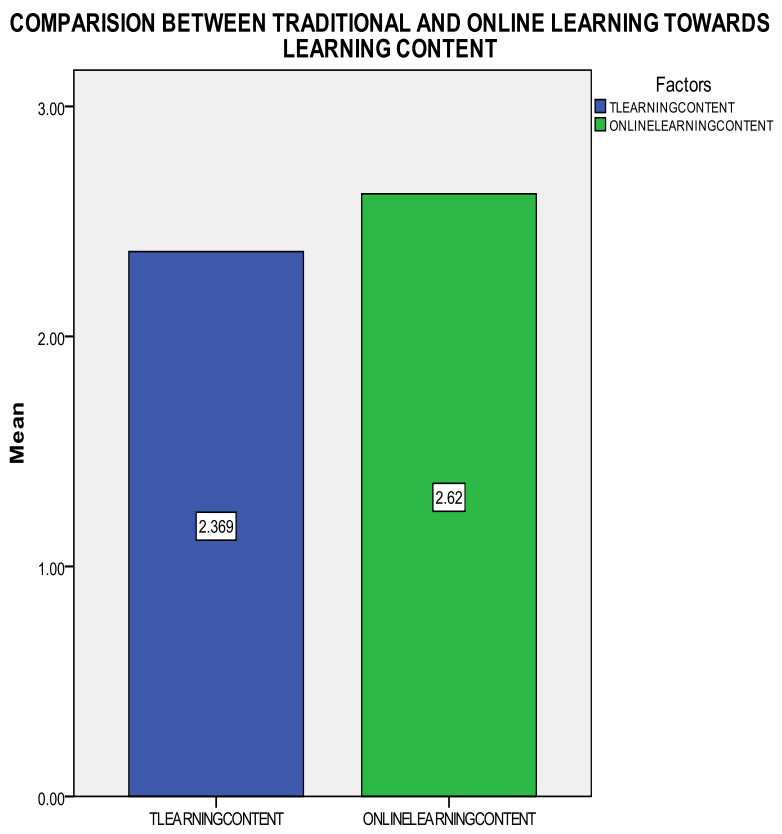

Figure-10: Comparison between Traditional and Online Learning Content 


\subsection{Comparision Between Traditional And Online Learning Towards Traditional Teacher And Online Reachability}

Table-9 and Figure-11 describes the comparative analysis of traditional and online learning towards course.

Table-9: Learning reachability comparison between Traditional and Online Learning

\begin{tabular}{|c|c|}
\hline TEACHER \& REACHABILITY & MEAN \\
\hline Traditional & 2.39 \\
\hline Online & 2.49 \\
\hline
\end{tabular}

Source: Primary data

From Table-9 and Figure-11 shows a comparative analysis was made between traditional and online learning on the parameter of reach ability. The Mean Value of Traditional Learning Teacher is 2.39 and that of Online learning reach ability is 2.49. It is evident that the online learning reach ability is more effective than traditional teacher who teach in the class. The Mean Values of Traditional Learning Teacher were observed and found that the Subject Knowledge (Mean: 2.46) of the teacher is less than that of Online Learning Delivery of the learning content by the teacher(Mean:2.68). The Clarity(Mean: 2.38) in delivering the learning content by the teacher to the students in traditional learning is less than the students who learn the concepts by Clarity(Mean:2.58) is very high in online learning.

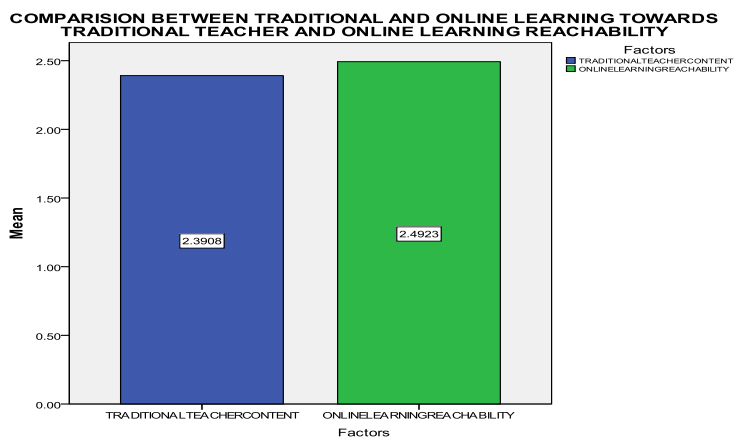

Figure-11: Comparison between Traditional Teacher and Online Reachability

\section{CONCLUSION}

The detailed process adopted in developing an intranet learning system known as "Knowledge-Connection" which is proposed for Computer Applications department. It acts as a supplement to the traditional teaching and learning methods. A detailed survey was conducted, on the subject of the development of intranet learning system by distributing a questionnaire to the teachers and students. Large number of responses came from teachers and students about the developments which gave us the enthusiasm for the positive approach towards the development of the learning tool "Knowledge-Connection". The analysis was conducted for developing the learning system, by designing through waterfall model, E-R Diagram and OOAD development life-cycle methodologies.
After a number of iterations and modifications, a final model of the learning system was made out of it. The coding is developed using Pre Hypertext Processor, Apache Web Server and Mysql as the back end and other tools such as Dream weaver and Flash was used The name is given as "Knowledge-Connection which helps the students in transforming online learning which is connected to their peers. The collaborative and interactive learning enhances the student's success in an online learning environment

At the end, questionnaire form was given to the students. A comparative analysis was made between traditional and online learning about the course was analyzed. It is evident that the online learning is more effective than traditional learning.

\section{REFERENCES}

[1] Improving the Quality of Technology-Enhanced Learning for Computer Programming Courses. Aisha A.Othman, Crinela Pislaru and Ahmed M.Impes. International Journal of Information and Education Technology, Vol.4, No.1, 83-88, February 2014.

[2] E-Learning Approach in Teaching Training, A.Seda Yucel. Turkish Online Journal of Distance Education-TOJDE, ISSN 1302-6488 Volume: 7 Number: 4 Article: 11, 1-8, July 2006.

[3] Blended learning using video-based blogs: Public speaking for English as a second language students, Ru-Chu Shih. Australasian Journal of Educational Technology, 26(6), 883-897, 2010

[4] Implementation of a Blended-Learning Course as Part of Faculty Development, Daniel Tolks, Iwona Pelczar, Daniel Bauer, Thomas Brendel, Anja Görlitz, Julia Küfner, Angelika Simonsohn and Inga Hege. Creative Education, 5, 948-953, 2014.

[5] IT Enabled Teaching over Traditional Classroom Teaching, Ghanshyam and Inder Singh Thakur. International Journal of Advanced Research in Computer Science and Software Engineering, Vol.3, Issue 5, ISBN:2277 128X, 104-107, May 2013.

[6] Teaching Hybrid Courses across disciplines: Effectively Combining Traditional Learning and e-learning pedagogies, Jonathan $\mathrm{H}$. Westover and Jacque $P$. Westover. International Journal of Information and Education Technology, Vol.4, Issue 1, 93-96, February 2014.

[7] Application Learning Content Management Systems, Virtual Classroom and M-learning in enterprises, Muzafer Saracevic, Esad Međedović, Sead Mašović, Faruk Selimović, Hamza Kamberović. ICT for SME 319-327, 2011.

[8] Online and Traditional Formative Assessment: Experience from a First-Year Property Course, Sharon Yam and Peter Rossini. 19 ${ }^{\text {th }}$ Annual Pacific RIM Real Estate Society Conference, Australia, 1-19, 13-16, January 2013.

[9] A Case Study on e-Learners Perception and Kansei Experience towards PedagogicalVirtual Agents, Chandra

[10] Reka Ramachandiran and Nazean Jomhari, Indian Journal of Science and Technology, ISSN: 0974-5645, Vol 8(11), 706311-10, June 2015. 